\title{
Versican expression is associated with tumor-infiltrating CD8-positive $T$ cells and infiltration depth in cervical cancer
}

\author{
Arko Gorter ${ }^{1}$, Henry J Zijlmans ${ }^{2}$, Hestia van Gent ${ }^{1}$, J Baptist Trimbos ${ }^{3}$, Gert J Fleuren ${ }^{1}$ \\ and Ekaterina S Jordanova ${ }^{1}$ \\ ${ }^{1}$ Department of Pathology, Leiden University Medical Center, Leiden, The Netherlands; ${ }^{2}$ Department of \\ Gynaecology, University Medical Center Groningen, University of Groningen, Groningen, The Netherlands \\ and ${ }^{3}$ Department of Gynaecology, Leiden University Medical Center, Leiden, The Netherlands
}

\begin{abstract}
Cervical carcinoma is the second most frequent cancer type in women worldwide. Both inflammatory cells and stromal cells are important for tumor progression. Stromal cells produce growth factors and extracellular matrix and provide an adequate environment for angiogenesis. Versican, a member of the extracellular matrix, has been shown to have a role in tumor progression. The aim of this study was to investigate versican expression, and its association with tumor-infiltrating inflammatory cell subsets and with clinicopathological parameters in human cervical cancers. We have studied the expression of versican in 149 cervical cancers using immunohistochemistry and mRNA in situ hybridization. Versican was predominantly expressed in the stroma (myofibroblasts). Using quantitative real-time-PCR, Vo was found to be the most prominent isoform. High stromal versican expression was significantly associated with a low number of tumor-infiltrating $T$ cells $(P=0.018)$ and particularly a low number of CD8-positive T cells (cytotoxic T cells; $P=0.002)$. Stromal versican expression was significantly higher in patients with an infiltration depth $>14 \mathrm{~mm}(P=0.004)$ and in patients with parametrial invasion $(P=0.044)$. Stromal versican expression was not associated with survival. Our results suggest that versican expression in the stromal compartment of cervical cancers results in reduced numbers of intraepithelial CD8-positive T cells and enhanced local invasion.
\end{abstract}

Modern Pathology (2010) 23, 1605-1615; doi:10.1038/modpathol.2010.154; published online 20 August 2010

Keywords: cervical cancer; invasion; versican

Cervical carcinoma is the second most common cancer type in women worldwide. ${ }^{1}$ It is caused by a persistent infection with high-risk human papillomavirus (HPV) types. Next to malignant epithelial cells, this tumor consists of inflammatory cells and stromal cells. Both inflammatory and stromal cells are important for tumor progression. ${ }^{2,3}$ In cervical carcinoma there is a high amount of inflammatory infiltrate, and we have recently shown a correlation between a high number of intraepithelial regulatory T cells (Treg) and poor survival of cervical carcinoma patients. ${ }^{4}$ Stromal cells produce growth factors and extracellular matrix (ECM) components and provide an adequate environment for angiogenesis.

Correspondence: Dr A Gorter, PhD, Department of Pathology, Leiden University Medical Center, P.O. Box 9600, 2300 RC Leiden, The Netherlands.

E-mail: A.Gorter@lumc.nl

Received 21 April 2010; revised and accepted 11 June 2010; published online 20 August 2010
One of these ECM components is versican, which is a member of the large aggregating chondroitin sulfate proteoglycan (CSPG) family that has been implicated in tumor progression. ${ }^{5}$ Versican is composed of a N-terminal globular G1 domain, a central glycosaminoglycan attachment region (GAG) and a C-terminal selectin-like G3 domain. ${ }^{6}$ Four isoforms are generated by alternative splicing: V0 containing both GAG $\alpha$ and GAG $\beta$ domains, V1 containing the GAG $\alpha$ domain, V2 containing the GAG $\beta$ domain and V3 consisting only of the globular domains. ${ }^{7}$ Recently, a fourth isoform, V4, has been found in breast cancer. ${ }^{8}$ The different isoforms are implicated in different biological processes. The V0 isoform is highly expressed during embryonic development, ${ }^{9}$ whereas in adult human tissues the V1 isoform is most prevalent. ${ }^{10} \mathrm{V0}$ and V1 are also the predominant isoforms found in cancer tissue. ${ }^{11-14}$ Versican expression promotes tumor growth by destabilizing focal cell contacts, thus hampering cell adhesion and regulating angiogenesis. ${ }^{10,15}$ Indeed, increased 
levels of versican have been reported in different tumor types such as adenocarcinomas, ${ }^{16-18}$ squamous cell carcinomas, ${ }^{19,20}$ sarcomas, ${ }^{21}$ mesotheliomas $^{22}$ and malignant melanomas. ${ }^{23}$ In addition, versican expression has been associated with tumor progression and decreased survival in various tumor types. $^{24-26}$ In cervical cancer, versican has been suggested to enhance tumor invasion and metastases formation. ${ }^{20}$

In this study, we have investigated the presence, isotype and location of versican in cervical carcinoma. We have determined the association between the presence of versican and the presence of different tumor-infiltrating inflammatory cell subsets. In addition, we have investigated the association of versican with several clinicopathological parameters such as lymph node positivity and diseasefree and overall survival.

\section{Materials and methods}

\section{Tissue Samples}

A total of 149 patients treated with radical hysterectomy and bilateral pelvic lymph node dissection for uterine cervical cancer were included in this study. Patients did not receive preoperative radiotherapy or chemotherapy. Treatment occurred between 1985 and 1999. Tissues had been fixed routinely in $10 \%$ formalin and embedded in paraffin. All tissues were retrieved from the archives of the Department of Pathology, Leiden University Medical Center. Samples were used according to the guidelines of the ethical committee of the Leiden University Medical Center. Clinical parameters were stored in a prospective database (administered by the Department of Gynecology) containing over 200 items per patient. The patient characteristics are shown in Table 1.

\section{Immunohistochemistry}

Immunohistochemical analysis was performed on $4 \mu \mathrm{m}$ paraffin sections, mounted on aminopropylethoxysilane-coated slides. Sections were deparaffinized, rehydrated and treated with $0.3 \% \mathrm{H}_{2} \mathrm{O}_{2}$ in methanol for $20 \mathrm{~min}$ to block endogenous peroxidase activity. Antigen retrieval was performed (0.01 M citrate, $\mathrm{pH}$ 6.0) and sections were rinsed in phosphate-buffered saline (PBS). Subsequently, sections were stained for versican (overnight) using a 1:200 dilution of anti-human versican monoclonal antibody (clone 2B1, IgG1; Seikagaku Corporation, Tokyo, Japan) in PBS containing 1\% bovine serum albumin (BSA). The slides were next incubated with Powervision-Poly-HRP-goat anti-mouse/rat/rabbit IgG (Immunogenic, Duiven, The Netherlands) and immune complexes were visualized with diaminobenzidine. CD68-positive cells, CD1a (Langerhans cells)-positive intraepithelial cells or DC-LAMPpositive stromal dendritic cells were visualized as described previously. ${ }^{27}$

\section{Fluorescent Immunohistochemistry}

A double staining was performed with smooth muscle actin (SMA; clone ASM-1, IgG2a, 1:300; Oncogene Research Product, Boston, MA, USA) and mouse monoclonal anti-human versican (clone 2B1, IgG1, 1:200; Seikagaku Corporation) or mouse monoclonal anti-human cytokeratin (clone AE1/ AE3, IgG1, 1:500; Dako Netherlands BV, Heverlee,

Table 1 Clinicopathological patient characteristics

\begin{tabular}{|c|c|c|c|}
\hline Clinicopathological variable & Category & $\mathrm{N}(\%)^{\mathrm{a}}$ & Association with high versican expression (P) \\
\hline FIGO & $\begin{array}{l}\text { IB1 } \\
\text { IB2/IIA }\end{array}$ & $\begin{array}{l}59(46) \\
69(54)\end{array}$ & 0.831 \\
\hline Histology & $\begin{array}{l}\text { Squamous } \\
\text { Adeno/adenosquamous }\end{array}$ & $\begin{array}{r}111(77) \\
34(23)\end{array}$ & 0.391 \\
\hline Lymph node metastasis & $\begin{array}{l}\text { No } \\
\text { Yes }\end{array}$ & $\begin{array}{l}98(66) \\
50(34)\end{array}$ & 0.078 \\
\hline Largest tumor diameter & $\begin{array}{l}<40 \mathrm{~mm} \\
\geq 40 \mathrm{~mm}\end{array}$ & $\begin{array}{l}67(49) \\
70(51)\end{array}$ & 0.465 \\
\hline Vasoinvasion & $\begin{array}{l}\text { No } \\
\text { Yes }\end{array}$ & $\begin{array}{l}56(40) \\
84(60)\end{array}$ & 0.205 \\
\hline Infiltration depth & $\begin{array}{l}<15 \mathrm{~mm} \\
\geq 15 \mathrm{~mm}\end{array}$ & $\begin{array}{l}82(58) \\
60(42)\end{array}$ & 0.004 \\
\hline Parametrial invasion & $\begin{array}{l}\text { No } \\
\text { Yes }\end{array}$ & $\begin{array}{r}123(83) \\
25(17)\end{array}$ & 0.044 \\
\hline HPV type & $\begin{array}{l}\text { HPV 16/18 } \\
\text { Other }\end{array}$ & $\begin{array}{r}101(81) \\
23(19)\end{array}$ & 0.963 \\
\hline Recurrent disease & $\begin{array}{l}\text { No } \\
\text { Yes }\end{array}$ & $\begin{array}{l}87(60) \\
59(40)\end{array}$ & 0.937 \\
\hline
\end{tabular}

${ }^{\mathrm{a}} N<149$ because data were not reported in the patient's chart.

Bold values indicate $P<0.05$. 
Belgium). Furthermore, a double staining with mouse monoclonal anti-human versican and mouse monoclonal anti-CD8 (clone 4B11, IgG2b, 1:400; Novocastra Laboratories, Newcastle upon Tyne, UK) was performed. Antigen retrieval with $0.01 \mathrm{M}$ citrate, pH 6.0 was performed by boiling the slides for $10 \mathrm{~min}$ in a microwave.

The primary antibodies were diluted in PBS/ $2 \%$ BSA in one mixture. The slides were incubated overnight with this mixture (100 $\mu$ l per sample). The next day, the slides were washed with PBS. The slides were then incubated for $1 \mathrm{~h}$ with the secondary antibodies $(100 \mu \mathrm{l}$ per sample; goat-anti-mouse IgG2a ALEXA 546 (red), 1:200; goat-anti-mouse IgG1 ALEXA 488 (green), 1:200; and goat-anti-mouse IgG2b ALEXA 647 (blue), 1:200). All ALEXA antibodies were obtained from Invitrogen (Invitrogen, Breda, The Netherlands). After this, the slides were washed with PBS and then mounted with MOWIOL.

\section{mRNA In Situ Hybridization}

Primers were chosen on the basis of the versican mRNA sequence (GenBank accession number GI_28144902): 5'-CAAGCATCCTGTCTCACGAA-3' (sense) and $5^{\prime}$-TTGGTATGCAGATGGGTTCA-3' (antisense). Probes were prepared and cervical carcinoma sections were stained for versican mRNA as previously described. ${ }^{28}$ In short, $3 \mu \mathrm{m}$ paraffin sections were pre-treated and hybridized with $100 \mathrm{ng} / \mathrm{ml}$ digoxigenin-labeled mRNA probe diluted in hybridization mixture containing $0.3 \mathrm{M} \mathrm{NaCl}$ and $0.03 \mathrm{M}$ saline sodium citrate (SSC). Hybridization was allowed for $16 \mathrm{~h}$ at $55^{\circ} \mathrm{C}$ in a humidified chamber. Slides were washed for $30 \mathrm{~min}$ in $50 \%$ formamide/ $2 \times$ SSC at $42{ }^{\circ} \mathrm{C}$, followed by $45 \mathrm{~min}$ in $0.1 \times$ SSC with $20 \mathrm{mM} \beta$-mercaptoethanol at $50^{\circ} \mathrm{C}$ and for 30 min with $2 \mathrm{U} / \mathrm{ml}$ ribonuclease T1 (Roche Diagnostics $\mathrm{GmbH}$, Mannheim, Germany) in $2 \times$ SSC, $1 \mathrm{mM}$ EDTA at $37^{\circ} \mathrm{C}$. RNA hybrids were detected using subsequently mouse anti-digoxigenin (1:2000; SigmaAldrich Chemie GmbH, Steinham, Germany), rabbit anti-mouse immunoglobulin (1:50; DAKO, Glostrup, Denmark) and mouse alkaline phosphatase antialkaline phosphatase (DAKO, Glostrup, Denmark). A cervical cancer sample stained for TGF- $\beta 1$ mRNA served as a positive control.

\section{Evaluation of Immunohistochemical Staining and mRNA In Situ Hybridization}

Versican expression was scored as described by Ruiter et al. ${ }^{29}$ Intensity was scored as none (0), mild (1), moderate (2) or intense (3) at low magnification $(\times 100)$. Furthermore, the percentage of positive tumor cells was determined and divided into groups: $0 \%$ (0, absent), $1-5 \%$ (1, sporadic), $6-25 \%$ (2, local), $26-50 \%$ (3, occasional), $51-75 \% \quad$ (4, majority) and $76-100 \%$ (5, large majority). The two
Table 2 Primer sequences for qRT-PCR

\begin{tabular}{ll}
\hline Gene & Sequence size $(\mathrm{bp})$ \\
\hline \multirow{2}{*}{ EEF1A1 } & F: 5'-CTGGCAAGGTCACCAAGTCT-3' (99) \\
& R: 5'-CCGTTCTTCCACCACTGATT-3' \\
Versican Vo & F: 5'-CCAGCAAGCACAAAATTTCA-3' (162) \\
& R: 5'-TGCACTGGATCTGTTTCTTCA-3' \\
Versican V1 & F: 5'-CCCAGTGTGGAGGTGGTCTAC-3' (124) \\
& R: 5'-CGCTCAAATCACTCATTCGACGTT-3' \\
Versican V2 & F: 5'-TCAGAGAAAATAAGACAGGACCTGATC-3' (135) \\
& R: 5'-CATACGTAGGAAGTTCAGTAGGATAACA-3' \\
Versican V3 & F: 5'-CCCTCCCCTGATAGCAGAT-3' (71) \\
& R: 5'-GGCACGGGGTTCATTTTGC-3' \\
\hline
\end{tabular}

parameters were combined, representing the sum of both the percentage and the staining intensity of the positive cells, which resulted in an overall score (0 or 2-8). The scores were combined into two groups: category 0 (score $0-5$, low expression) and category 1 (score 6-8, high expression). Expression was scored by two independent researchers without knowing the identity and clinical outcome of patients. The data on T-cell infiltration in this patient series were previously published. ${ }^{4}$

\section{Quantitative Real-Time-PCR (qRT-PCR)}

In all, $2 \mu \mathrm{g}$ of total RNA was transcribed to cDNA with Superscript II reverse transcriptase (Life Technologies, Grand Island, NY, USA). Amplification reactions were performed with qPCR Core kit for SYBR Green (Eurogentec, Hampshire, UK) according to the manufacturer's protocol. Fluorescent PCR analysis was performed using the BIO-RAD iCycler (BIO-RAD, Hercules, CA, USA). The following PCR conditions were used: $10 \mathrm{~min}$ at $95{ }^{\circ} \mathrm{C}$, followed by 45 cycles of $15 \mathrm{~s}$ at $95^{\circ} \mathrm{C}$ and $1 \mathrm{~min}$ at the appropriate annealing temperature. The household gene EEF1A1 was used for normalization of the expression data. ${ }^{30}$ Primers were designed according to Zhao et al. ${ }^{31}$ Relative quantification was performed using standard curves, followed by adjustment with the normalization factor, which was calculated using the Genorm program. The primer sequences are listed in Table 2 .

\section{Statistical Analysis}

Statistical analysis was performed using SPSS 16.0 (SPSS, Chicago, IL, USA). Data were processed using the $\chi^{2}$ test, Student's t-test, the Mann-Whitney $U$-test or the Fisher's exact test, depending on the number and distribution of the compared groups. The $P<0.05$ was considered statistically significant.

\section{Results}

\section{Versican Is Predominantly Expressed in the Stroma}

First, we investigated the presence and location of versican in 149 cervical cancer specimens using 
immunohistochemistry. Versican expression was predominantly observed in the stroma (Figure 1a-d). The expression of versican showed a heterogeneous staining pattern and was more pronounced at the invasive border in 127 out of 142 cervical cancer specimens. In 62 out of 149 specimens,
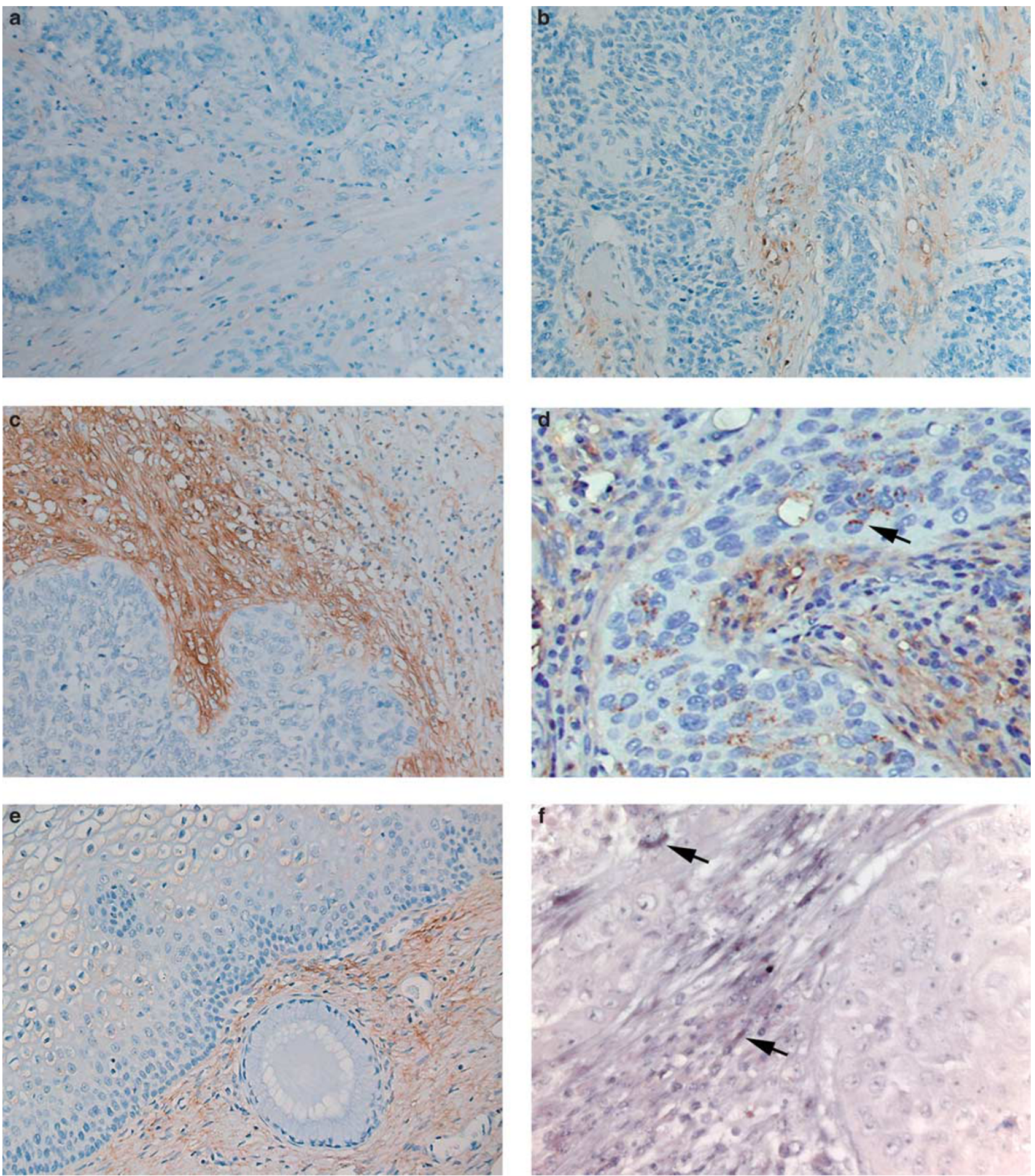

Figure 1 The expression and location of versican. The expression and location of versican was determined using immunohistochemistry as well as RNA-in situ hybridization as described in the Materials and methods ( $\times 250$ magnification). (a) Cervical tumor, weak versican staining; (b) cervical tumor, moderate stromal versican staining; (c) cervical tumor, strong stromal versican staining; and (d) cervical tumor, strong stromal versican staining $(\times 400$ magnification). The arrow indicates a positive tumor cell. (e) Subepithelial versican staining in normal cervical tissue and (f) RNA in situ hybridization cervical tumor with weak cytoplasmic staining of stromal cell clusters ( $\times 400$ magnification). Arrows indicate positive stromal cells. 
versican expression was also found in the cervical carcinoma cells (Figure 1d, arrow). Tumors without versican expression were not observed. To quantify the versican expression, the scoring system of Ruiter et $a l^{29}$ was used. Weak immunoreactivity (score 2-5) was observed in 93 cases, and strong immunoreactivity (score 6-8) was observed in 56 cases. As a control, the versican expression was determined in normal cervical tissue (Figure 1e). In this case, moderate expression of versican was found in the subepithelial tissue. As strong expression was found at the stromal-epithelial border, we determined whether tumor cell or (myo)fibroblast were associated with versican expression (Figure 2). For this purpose, immunofluorescent double staining with both anti-cytokeratin (tumor cells) and antiSMA (myofibroblasts) and versican was performed. None of the tumor cells expressed in addition to keratin SMA (Figure 2a). The majority of versican expression was associated with myofibroblasts and only a few versican-positive tumor cells were identified (Figure 2b). Strong versican expression was observed around blood vessels in the tumor stroma.

To determine whether the tumor or the stromal cells in cervical carcinomas produce versican, mRNA in situ hybridization was performed using placental tissue as a positive control. Placental tissue, strongly positive according to the qRT-PCR results, showed a weak staining at the tip of the villi. Only a weak expression of versican was detected in the cervical cancer tissue. The expression of versican in cervical cancer tissue was predominantly present in the stromal compartment (Figure 1f).

\section{The Vo Isoform Is Preferentially Expressed in Cervical Cancer}

Because versican can be expressed in different isoforms (V0, V1, V2 and V3), their expression was measured using qRT-PCR in 8 cervical cancer cell lines and 20 cervical carcinoma samples. Normal lung and placenta tissue served as a positive control. The expression level of each isoform was normalized to the household gene EEF1A1. From the cell lines investigated, CC10B expressed V0, V1 and V2, CSCC7 expressed V1 and HeLa expressed V3. CaSki, CSCC1, CC8, CC11 and SiHa did not express versican. To verify the mRNA expression pattern, versican protein expression was determined on cytospin preparations from CC10B and Caski. As expected, only CC10B showed prominent versican expression (data not shown). Previously, we have performed a cDNA microarray analysis on 32 tumor specimens. ${ }^{32}$ All the cervical cancer samples examined in that study expressed versican (data not shown). In the present study, we have investigated the versican isoforms expressed in 20 tumor samples. V0 was found to be the most prominent isoform (Figure 3).
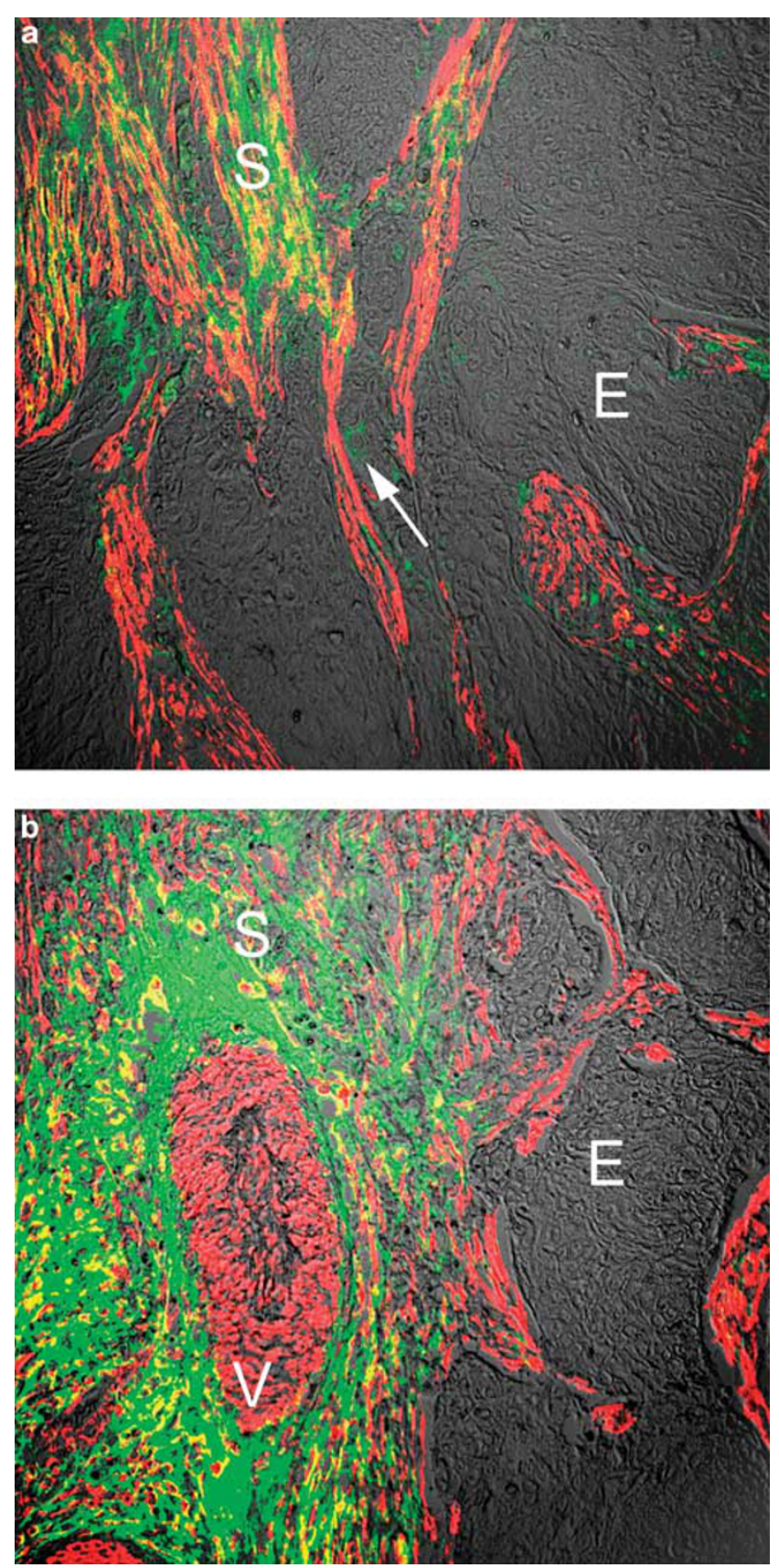

Figure 2 The expression and location of versican by stromal cells and tumor cells. The expression and location of versican and smooth muscle actin (SMA) was determined using fluorescent immunohistochemistry as described in the Materials and methods ( $\times 250$ magnification). (a) Cervical tumor, strong stromal versican staining (green) and strong stromal SMA staining (red); the arrow indicates positive tumor cells, colocalization of versican and SMA in stromal cells (yellow). (b) Cervical tumor, strong stromal versican staining (green) and strong SMA staining of vessels (red). E, epithelial tumor cells; S, stroma; V, vessel.

\section{High Versican Expression Is Associated with a Decreased Number of Intraepithelial CD8-Positive T Cells}

As the composition of the ECM influences the migration of inflammatory cells, ${ }^{33}$ we have also measured the association between inflammatory 
cells and versican expression. A statistically significant association was observed for tumors with a minor/moderate number of infiltrating inflammatory cells and tumors showing high versican expression $(P=0.009$; Table 3$)$. Subsequently, we investigated whether this could be attributed to a particular chronic inflammatory cell subpopulation. Cell numbers were counted both in the stromal and intraepithelial compartments. No statistically significant association was observed for tumors with a low (based on the median) number of tumorassociated macrophages (CD68-positive cells, both stromal and intraepithelial), Langerhans cells (CD1a-positive cells; intraepithelial) or dendritic cells (DC-LAMP-positive cells; stromal) or NK cells and high versican expression. A statistically significant association between tumors with a low total number of intraepithelial CD3-positive $\mathrm{T}$ cells $(P=0.018)$ and tumors with high versican expression was observed. No statistically significant association was observed for tumors with a low

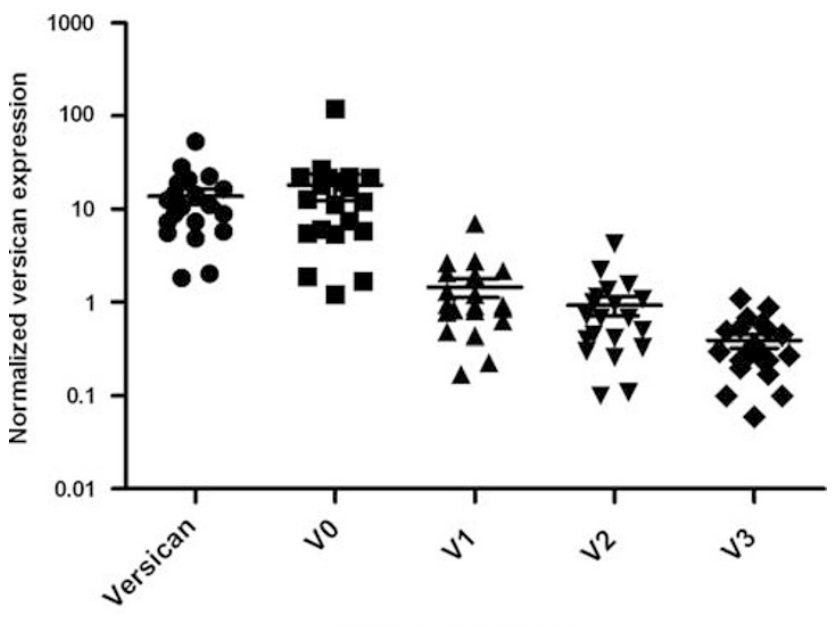

Versican isoform

Figure 3 The expression of versican isoforms in cervical cancer. Isoform expression was measured with qRT-PCR in 20 cervical specimens as described in the Materials and methods. Versican expression was normalized against a household gene (EEF1A1). number of CD4-positive T cells, a low number of Treg cells or a low number of NKT1 cells and tumors with high versican expression. However, a strengthened statistically significant association between tumors with a low number of intraepithelial CD8-T cells $(P=0.002)$ and tumors with high versican expression was observed. Using two-color confocal microscopy we could confirm this relationship (Figure 4). Indeed, tumors with a high versican expression showed a lower number of intraepithelial CD8-positive T cells (Figure $5, P<0.018$, Student's $t$-test).

\section{Versican Expression Is Correlated with Infiltration Depth}

As an association was found between high numbers of CD8-positive T cells and limited expression of versican, we determined whether this was also reflected in an association with clinical parameters. We have associated high or low versican expression with FIGO stage, lymph node metastasis, tumor size, infiltration depth, vascular space involvement, parametrial invasion, HPV status and histology (Table 1). Tumors with high versican expression were significantly associated with an infiltration depth of $\geq 15 \mathrm{~mm}(P=0.004)$ and parametrial invasion $(P=0.044)$. However, no statistically significant association between patients with tumors with high versican expression and patient survival was observed.

\section{Discussion}

In this study, we have investigated the expression of versican in cervical cancer and have correlated its expression with the presence of inflammatory cells and clinicopathological parameters. As observed by Kodama et $a l,{ }^{20}$ versican is predominantly expressed in the stromal compartment, although occasionally tumor cells are also positive. As previously shown for breast tumors, in cervical tumors also intense versican staining was observed in the peripheral area of the tumors. ${ }^{34}$ Using immunofluorescent

Table 3 Association between inflammatory cell subpopulations and versican expression

\begin{tabular}{|c|c|c|c|c|}
\hline Cell population & Location & $\mathrm{N}$ & Median $\left(\mathrm{mm}^{2}\right)$ & Association with high versican expression (P) \\
\hline Minor/moderate infiltration & IE+stroma & 101 & NA & 0.009 \\
\hline Tumor-associated macrophages & Stroma & 33 & 156 & 1.000 \\
\hline Tumor-associated macrophages & $\mathrm{IE}$ & 33 & 57 & 0.695 \\
\hline Dendritic cells & Stroma & 33 & 1 & 0.418 \\
\hline Langerhans cells & $\mathrm{IE}$ & 33 & 33 & 0.238 \\
\hline NK cells & $\mathrm{IE}$ & 74 & 0 & 0.918 \\
\hline T cells (low numbers) & IE+stroma & 74 & 180 & 0.018 \\
\hline CD4-positive T cells & $\mathrm{IE}$ & 74 & 36 & 0.573 \\
\hline Regulatory T cells & Stroma & 70 & 24 & 0.508 \\
\hline Regulatory T cells & IE & 70 & 4 & 0.060 \\
\hline NKT1 cells & $\mathrm{IE}$ & 74 & 25 & 0.058 \\
\hline CD8-positive T cells (low numbers) & IE & 74 & 94 & 0.002 \\
\hline
\end{tabular}

Abbreviations: NA, not applicable; IE, intraepithelial.

Bold values indicate $P<0.05$. 
double staining, we have shown that versican expression was associated with myofibroblasts. We have demonstrated that the predominant versican isotype in cervical cancer is V0. Previously, V0 and V1 were reported to be the predominant isoforms in other epithelial cancer types such as breast and prostate cancer. ${ }^{8,11-14}$ The V1 isoform has been shown to enhance cell proliferation and to protect fibroblasts from apoptosis. ${ }^{35}$ Increased levels of versican have been found in brain tumors, cervical carcinomas, melanomas, breast cancer, prostate cancer, colorectal cancer, lung cancer, pancreatic cancer, endometrial cancer, oral cancer and ovarian cancer. ${ }^{12,13,16-18,20,23,34,36-39}$

As the composition of the ECM influences the migration of inflammatory cells, ${ }^{33}$ we have also measured the association between inflammatory cells and versican expression. Despite the reported production of versican isoforms $\mathrm{V} 0$ and $\mathrm{V} 1$ by human leukemic monocytes ${ }^{40}$ and the reported
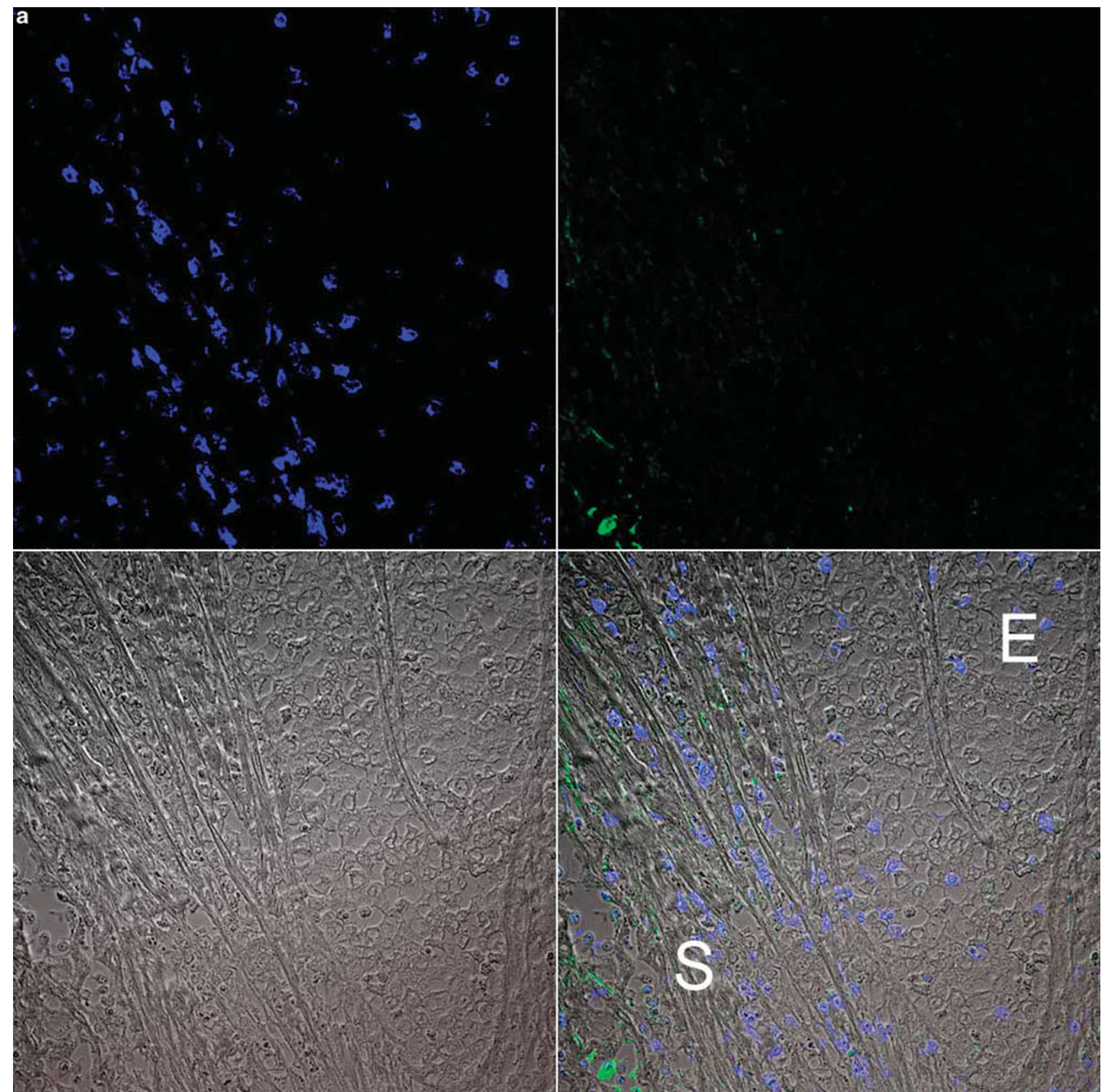

Figure 4 The expression of versican and location of CD8-positive T cells. Expression of versican (green) and location of CD8-positive T cells was determined using fluorescent immunohistochemistry as described in the Materials and methods $(\times 250$ magnification). The tumor is visualized as a phase-contrast Nomarski image (gray). (a) Cervical tumor, weak versican staining in the peripheral stromal area (green) was associated with a high number of intraepithelial CD8-positive T cells (blue). (b) Cervical tumor, strong versican staining in the peripheral stromal area (green) was associated with a low number of intraepithelial CD8-positive T cells (blue). E, epithelial tumor cells; S, stroma. 


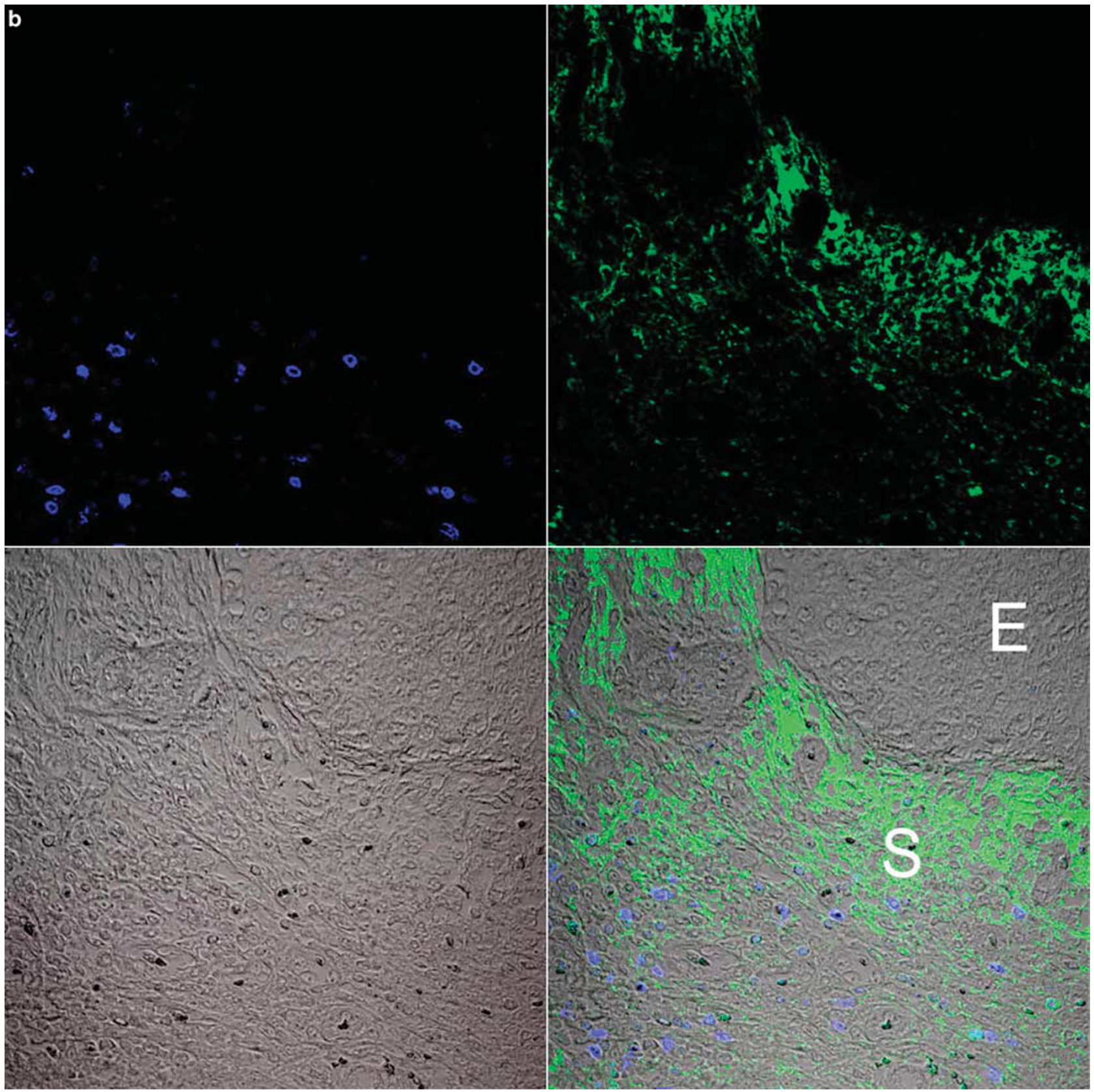

Figure 4 Continued.

increased synthesis of versican by hypoxic macrophages, no significant statistical association was observed for stromal or intraepithelial CD68-positive cells in our study. Recently, in a rat experimental model, fragments of versican were shown to activate TLR2-positive macrophages. ${ }^{41}$ We could demonstrate TLR2-positive macrophages in both the stroma and within the epithelial compartment (data not shown); however, no statistically significant association between versican expression and the presence of TLR2-positive macrophages was observed. In addition, we did not find an association between TLR2-positive macrophages and TNF $\alpha$ expression (data not shown). However, a statistically significant correlation between tumors with a low number of intraepithelial $\mathrm{T}$ cells and tumors with high versican expression was shown. Versican is known to bind several cytokines and chemokines, such as XCL1 (Lymphotactin), CCL5 (RANTES), CCL20 (LARC) and CCL21 (SLC), all of which are potent T-cell chemoattractants. ${ }^{42}$ It is noteworthy that CCL5 expression has been associated with CD8positive T-cell infiltration ${ }^{43}$ and that mouse 6Ckine (CCL21 in humans) when transfected into a colon carcinoma cell line has both antitumor activity mediated by CD8-positive $\mathrm{T}$ cells and angiostatic effects. ${ }^{44}$ This suggests that versican might act as a molecular sink, trapping CCL5 and CCL21, and offers 


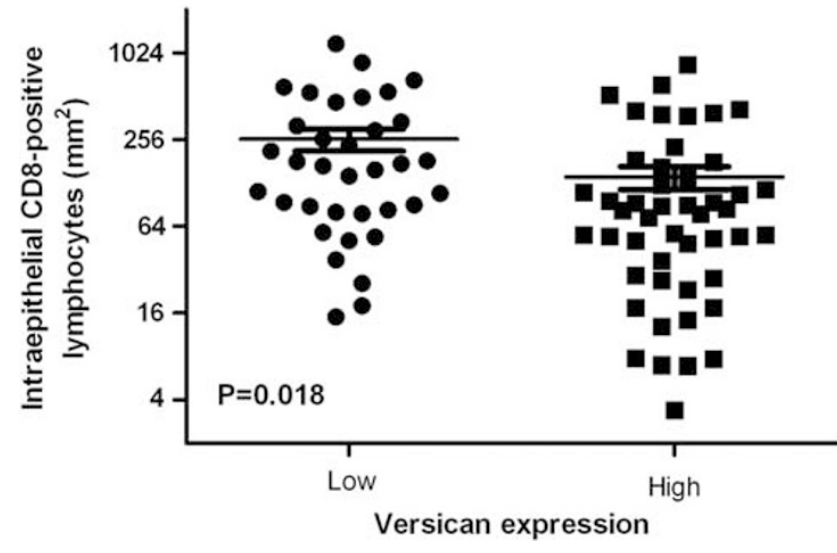

Figure 5 Association between versican expression and intraepithelial CD8-positive T cells. Versican and CD8 expression were determined using (fluorescent) immunohistochemistry as described in the Materials and methods. Immunohistochemical versican scores were combined into two groups: low versican expression (score 0-5) and high versican expression (score 6-8), as described in the Materials and methods. CD8-positive T cells were quantified as described in the Materials and methods and expressed as number per $\mathrm{mm}^{2}$.

an explanation for the reciprocal relationship between versican expression and the presence of CD8-positive T cells.

We also have associated the expression of versican with relevant clinical parameters such as lymph node metastasis, tumor size, infiltration depth and vascular space involvement. Although for breast, cervical, prostate and other tumor types, increased versican expression has been associated with relapse and poor clinical outcome, ${ }^{12,16,17,19,20,36,39,45,46}$ we could not demonstrate this association in our cervical cancer cohort. To exclude that this was related to the scoring system, we have also scored our data according to the method described by Kodama et $a l^{20}$ (data not shown), but in this case also no statistically significant association was found. However, we did find a statistically significant association with an infiltration depth of $\geq 15 \mathrm{~mm}$ $(P=0.004)$. As there is a significant association between infiltration depth and survival, we stratified infiltration depth according to versican expression. The results show that (low or high) versican expression does not affect survival of cervical cancer patients with an infiltration depth of $<15 \mathrm{~mm}$, whereas in cervical cancer patients with infiltration depth of $\geq 15 \mathrm{~mm}$, low versican expression predicts a poorer survival. However, because of the limited number of cases $(n=60)$, the survival difference between patients with a low versican or a high versican expression in this subgroup of cervical cancer patients was not significant (data not shown).

In the studies of Kodama et $a l^{20,45}$ the depth of stromal invasion (cervical cancer) and myometrial invasion (endometrial cancer) was also associated with versican expression, although in both studies only a trend ( $P=0.069$ and $P=0.052$, respectively) was observed. However, experimental support for a role of versican in invasion was provided by functional studies demonstrating that versican is able to increase cancer cell motility ${ }^{47}$ and to reduce the attachment of cancer cells to fibronectin-coated surfaces. ${ }^{48}$

In conclusion, our results suggest that modulation of the ECM composition in the peripheral stromal area of cervical cancers influences the migration of cytotoxic T cells and enhances local invasion of the tumor cells.

\section{Acknowledgement}

We thank Anne Bijnsdorp for her help in studying the expression of TLR2 on macrophages.

\section{Disclosure/conflict of interest}

The authors declare no conflict of interest.

\section{References}

1 Parkin DM, Bray F, Ferlay J, et al. Global cancer statistics, 2002. CA Cancer J Clin 2005;55:74-108.

2 Mbeunkui F, Johann Jr DJ. Cancer and the tumor microenvironment: a review of an essential relationship. Cancer Chemother Pharmacol 2009;63:571-582.

3 Coussens LM, Werb Z. Inflammation and cancer. Nature 2002;420:860-867.

4 Jordanova ES, Gorter A, Ayachi O, et al. Human leukocyte antigen class I, MHC class I chain-related molecule A, and CD8+/regulatory T-cell ratio: which variable determines survival of cervical cancer patients? Clin Cancer Res 2008;14:2028-2035.

5 Ricciardelli C, Sakko AJ, Ween MP, et al. The biological role and regulation of versican levels in cancer. Cancer Metastasis Rev 2009;28:233-245.

6 Wight TN. Versican: a versatile extracellular matrix proteoglycan in cell biology. Curr Opin Cell Biol 2002;14:617-623.

7 Lemire JM, Braun KR, Maurel P, et al. Versican/PG-M isoforms in vascular smooth muscle cells. Arterioscler Thromb Vasc Biol 1999;19:1630-1639.

8 Kischel P, Waltregny D, Dumont B, et al. Versican overexpression in human breast cancer lesions: known and new isoforms for stromal tumor targeting. Int J Cancer 2010;126:640-650.

9 Perissinotto D, Iacopetti P, Bellina I, et al. Avian neural crest cell migration is diversely regulated by the two major hyaluronan-binding proteoglycans PG-M/versican and aggrecan. Development 2000;127:2823-2842.

10 Cattaruzza S, Schiappacassi M, Ljungberg-Rose A, et al. Distribution of PG-M/versican variants in human tissues and de novo expression of isoform V3 upon endothelial cell activation, migration, and neoangiogenesis in vitro. J Biol Chem 2002;277:47626-47635.

11 Sakko AJ, Ricciardelli C, Mayne K, et al. Versican accumulation in human prostatic fibroblast cultures is enhanced by prostate cancer cell-derived transforming growth factor beta1. Cancer Res 2001;61:926-930.

12 Ricciardelli C, Brooks JH, Suwiwat S, et al. Regulation of stromal versican expression by breast cancer cells 
and importance to relapse-free survival in patients with node-negative primary breast cancer. Clin Cancer Res 2002;8:1054-1060.

13 Nikitovic D, Zafiropoulos A, Katonis P, et al. Transforming growth factor-beta as a key molecule triggering the expression of versican isoforms v0 and v1, hyaluronan synthase-2 and synthesis of hyaluronan in malignant osteosarcoma cells. IUBMB Life 2006;58:47-53.

14 Arslan F, Bosserhoff AK, Nickl-Jockschat T, et al. The role of versican isoforms $\mathrm{V0} / \mathrm{V} 1$ in glioma migration mediated by transforming growth factor-beta2. Br J Cancer 2007;96:1560-1568.

15 Yang BL, Zhang Y, Cao L, et al. Cell adhesion and proliferation mediated through the G1 domain of versican. J Cell Biochem 1999;72:210-220.

16 Pirinen R, Leinonen $\mathrm{T}$, Bohm J, et al. Versican in nonsmall cell lung cancer: relation to hyaluronan, clinicopathologic factors, and prognosis. Hum Pathol 2005;36:44-50.

17 Suwiwat S, Ricciardelli C, Tammi R, et al. Expression of extracellular matrix components versican, chondroitin sulfate, tenascin, and hyaluronan, and their association with disease outcome in nodenegative breast cancer. Clin Cancer Res 2004;10: 2491-2498.

18 Voutilainen K, Anttila M, Sillanpaa S, et al. Versican in epithelial ovarian cancer: relation to hyaluronan, clinicopathologic factors and prognosis. Int J Cancer 2003;107:359-364.

19 Pukkila MJ, Kosunen AS, Virtaniemi JA, et al. Versican expression in pharyngeal squamous cell carcinoma: an immunohistochemical study. J Clin Pathol 2004;57: 735-739.

20 Kodama J, Hasengaowa, Kusumoto T, et al. Versican expression in human cervical cancer. Eur J Cancer 2007;43:1460-1466.

21 Isogai Z, Shinomura T, Yamakawa N, et al. 2B1 antigen characteristically expressed on extracellular matrices of human malignant tumors is a large chondroitin sulfate proteoglycan, PG-M/versican. Cancer Res 1996;56:3902-3908.

22 Gulyas M, Hjerpe A. Proteoglycans and WT1 as markers for distinguishing adenocarcinoma, epithelioid mesothelioma, and benign mesothelium. J Pathol 2003;199:479-487.

23 Touab M, Villena J, Barranco C, et al. Versican is differentially expressed in human melanoma and may play a role in tumor development. Am J Pathol 2002;160:549-557.

24 Skandalis SS, Theocharis AD, Theocharis DA, et al. Matrix proteoglycans are markedly affected in advanced laryngeal squamous cell carcinoma. Biochim Biophys Acta 2004;1689:152-161.

25 Theocharis AD. Human colon adenocarcinoma is associated with specific post-translational modifications of versican and decorin. Biochim Biophys Acta 2002;1588:165-172.

26 Theocharis AD, Tsara ME, Papageorgacopoulou N, et al. Pancreatic carcinoma is characterized by elevated content of hyaluronan and chondroitin sulfate with altered disaccharide composition. Biochim Biophys Acta 2000;1502:201-206.

27 Zijlmans HJ, Fleuren GJ, Baelde HJ, et al. Role of tumor-derived proinflammatory cytokines GM-CSF, TNF-alpha, and IL-12 in the migration and differentiation of antigen-presenting cells in cervical carcinoma. Cancer 2007;109:556-565.
28 Zijlmans HJ, Fleuren GJ, Baelde HJ, et al. The absence of CCL2 expression in cervical carcinoma is associated with increased survival and loss of heterozygosity at 17q11.2. J Pathol 2006;208:507-517.

29 Ruiter DJ, Ferrier CM, van Muijen GN, et al. Quality control of immunohistochemical evaluation of tumour-associated plasminogen activators and related components. European BIOMED-1 Concerted Action on Clinical Relevance of Proteases in Tumour Invasion and Metastasis. Eur J Cancer 1998;34:1334-1340.

30 Kloth JN, Fleuren GJ, Oosting J, et al. Substantial changes in gene expression of Wnt, MAPK and TNFalpha pathways induced by TGF-beta1 in cervical cancer cell lines. Carcinogenesis 2005;26:1493-1502.

31 Zhao X, Russell P. Versican splice variants in human trabecular meshwork and ciliary muscle. Mol Vis 2005;11:603-608.

32 Kloth JN, Gorter A, Fleuren GJ, et al. Elevated expression of SerpinA1 and SerpinA3 in HLA-positive cervical carcinoma. J Pathol 2008;215:222-230.

33 Sandel MH, Dadabayev AR, Menon AG, et al. Prognostic value of tumor-infiltrating dendritic cells in colorectal cancer: role of maturation status and intratumoral localization. Clin Cancer Res 2005;11:2576-2582.

34 Nara Y, Kato Y, Torii Y, et al. Immunohistochemical localization of extracellular matrix components in human breast tumours with special reference to PGM/versican. Histochem J 1997;29:21-30.

35 Sheng W, Wang G, Wang Y, et al. The roles of versican V1 and V2 isoforms in cell proliferation and apoptosis. Mol Biol Cell 2005;16:1330-1340.

36 Ricciardelli C, Mayne K, Sykes PJ, et al. Elevated levels of versican but not decorin predict disease progression in early-stage prostate cancer. Clin Cancer Res 1998; 4:963-971.

37 Casey RC, Oegema Jr TR, Skubitz KM, et al. Cell membrane glycosylation mediates the adhesion, migration, and invasion of ovarian carcinoma cells. Clin Exp Metastasis 2003;20:143-152.

38 Mukaratirwa S, Koninkx JF, Gruys E, et al. Mutual paracrine effects of colorectal tumour cells and stromal cells: modulation of tumour and stromal cell differentiation and extracellular matrix component production in culture. Int J Exp Pathol 2005;86: 219-229.

39 Pukkila M, Kosunen A, Ropponen K, et al. High stromal versican expression predicts unfavourable outcome in oral squamous cell carcinoma. J Clin Pathol 2007;60:267-272.

40 Makatsori E, Lamari FN, Theocharis AD, et al. Large matrix proteoglycans, versican and perlecan, are expressed and secreted by human leukemic monocytes. Anticancer Res 2003;23:3303-3309.

41 Kim S, Takahashi H, Lin WW, et al. Carcinomaproduced factors activate myeloid cells through TLR2 to stimulate metastasis. Nature 2009;457:102-106.

42 Hirose J, Kawashima $\mathrm{H}$, Yoshie $\mathrm{O}$, et al. Versican interacts with chemokines and modulates cellular responses. J Biol Chem 2001;276:5228-5234.

43 Negus RP, Stamp GW, Hadley J, et al. Quantitative assessment of the leukocyte infiltrate in ovarian cancer and its relationship to the expression of C-C chemokines. Am J Pathol 1997;150:1723-1734.

44 Vicari AP, Ait-Yahia S, Chemin K, et al. Antitumor effects of the mouse chemokine 6Ckine/SLC through angiostatic and immunological mechanisms. J Immunol 2000;165:1992-2000. 
45 Kodama J, Hasengaowa, Kusumoto T, et al. Prognostic significance of stromal versican expression in human endometrial cancer. Ann Oncol 2007;18:269-274.

46 Hanekamp EE, Gielen SC, Smid-Koopman E, et al. Consequences of loss of progesterone receptor expression in development of invasive endometrial cancer. Clin Cancer Res 2003;9:4190-4199.
47 Ricciardelli C, Russell DL, Ween MP, et al. Formation of hyaluronan- and versican-rich pericellular matrix by prostate cancer cells promotes cell motility. J Biol Chem 2007;282:10814-10825.

48 Sakko AJ, Ricciardelli C, Mayne K, et al. Modulation of prostate cancer cell attachment to matrix by versican. Cancer Res 2003;63:4786-4791. 